\title{
LA LUCHA CONTRA EL ANDROCENTRISMO EN EL DESARROLLO SOCIOECONÓMICO: LA AGENDA INTERNACIONAL DE LAS MUJERES
}

\author{
Libertad Jiménez Almirante
}

Centro de Estudos Internacionais do Instituto Universitário de Lisboa

(CEI-IUL)

\section{RESUMEN}

En el presente artículo se hace, por un lado, un análisis teórico sobre la lucha contra el androcentrismo en la concepción del desarrollo socioeconómico pretendido por algunas agencias internacionales y, por el otro, desde un punto de vista socioeconómico, se aborda la influencia de los feminismos a través de la incorporación de la perspectiva de género como herramienta de análisis e intervención indispensable en el desarrollo propuesto por algunos organismos internacionales. En este sentido, la agenda internacional de las mujeres en el desarrollo ha sido determinada por una serie de enfoques diferenciados que han sido definidos desde una perspectiva asistencialista, como es el caso del "enfoque de bienestar"; desde una óptica economicista, como es el caso del "enfoque de mujeres en el desarrollo"; o desde un punto de vista analítico y transformador, como es el caso del "enfoque de género en el desarrollo" y del "enfoque de género y desarrollo humano".

\section{PALABRAS CLAVE}

Feminismos, Género, Desarrollo, Economía

\section{ABSTRACT}

Through this article we have tried, on the one hand, to carry out a theoretical analysis about the combating of androcentrism in the perception of socio-economic development sought by some international agencies and, on the other hand, to address the influence of feminism on the development proposed by some international organizations from a socioeconomic perspective, using the gender perspective as a key tool for analysis and intervention. In this regard, women's international agenda in 
development has been determined by a number of different approaches that have been defined from a welfare perspective, as in the case of the "welfare approach"; from an economic perspective, as it is the case for the "women in development approach"; or from an analytical and transforming point of view, as in the "gender in development" and in the "gender and human development approaches".

\section{KEY WORDS}

Feminisms, Gender, Development, Economy 


\section{INTRODUCCIÓN}

La consideración de la teoría de género en el análisis vinculado al desarrollo socioeconómico ideado por algunos organismos internacionales, principalmente a partir de la concepción del "enfoque de género en el desarrollo" (Sen, Grow, 1987), ha sido uno de los logros de los feminismos en el siglo XX. Dicho fruto se ha destacado debido a la necesidad de tener en cuenta que el bienestar de las personas tiene una base material muy importante determinada por el acceso y el control sobre los recursos necesarios para el desarrollo de la "agencia personal del individuo", como la denomina Sen (1985). Sin embargo, cuando la óptica de género en el desarrollo ha sido instrumentalizada por las agencias internacionales, ${ }^{1}$ lo ha sido sólo en un nivel retórico, por lo que se encuentra pendiente de su puesta en práctica real.

En este artículo, se lleva a cabo, por un lado, un análisis teórico sobre la lucha contra las imposiciones androcéntricas vertidas sobre el desarrollo socioeconómico pretendido por algunas agencias internacionales como, por ejemplo, el Fondo Monetario Internacional (FMI), el Banco Mundial (BM) o la Organización de las Naciones Unidas (ONU). Por otro lado, se aborda la influencia de los feminismos a través de la incorporación de la perspectiva de género en las arquitecturas desarrollistas propuestas por dichos organismos internacionales desde un punto de vista socioeconómico.

1 El concepto "agencia" se define como aquella organización administrativa especializada a la que se confía la gestión de un servicio. En este sentido, se ha considerado "agencia internacional para el desarrollo" a toda aquella organización multilateral a la que se le ha confiado la gestión del desarrollo del mundo a través del sistema de cooperación internacional.
Desde una óptica retrospectiva, la preocupación por el cuadrinomio "economía-mujeres-desarrolloandrocentrismo" es un asunto histórico que demoró décadas en ser tenido en cuenta tanto por los gobiernos nacionales como por la comunidad internacional. Fue Gilman una de las primeras autoras que reflexionó, desde el "feminismo evolutivo", sobre dicho cuadrinomio.

Yaen 1911, acerca del binomio "androcentrismodesarrollo", Gilman (2011 [1911]) argumentó, en relación con la descripción de la condición humana vista desde los ojos androcéntricos, que "ella" (en referencia a la condición humana de las mujeres) "ha ocupado siempre el lugar de una preposición en relación con el hombre. Ha sido considerada por encima de él, o por debajo de él, delante de él, detrás de él, a su lado, una existencia enteramente relativa"3 (Gilman, 2011 [1911]: 20).

Según la autora, esta concepción de la condición humana exclusivamente masculina coloca a los hombres como figuras centrales y dominantes en las siguientes áreas fundamentales para el desarrollo vital de los individuos: 1) frente al desarrollo humano, las mujeres son consideradas una subespecie de la raza humana dedicada únicamente a la reproducción; 2) la familia es la institución sobre la que los hombres organizan su "industria

2 El "feminismo evolutivo" de Gilman, de tipo socioeconómico, centra su esencialidad en el debate sobre la idea de progreso humano, es decir, sobre la consecución de la mejor versión de la humanidad. Dicho "feminismo evolutivo" presenta una parte de sus raíces en el "feminismo darwiniano" que incorpora la perspectiva de género a la teoría de la evolución, androcéntrica, de Charles Darwin. Una de las obras pioneras del "feminismo darwiniano" fue escrita por Brown Blackwell (1875), que pone de manifiesto la necesidad de aplicar la hipótesis de la selección natural también a las mujeres.

3 Mi traducción, del original en inglés. 
doméstica", eligiendo unilateralmente a aquella mujer (o mujeres) que le va (o van) a servir de garantía para el correcto funcionamiento de su "producción familiar"; 3) la inferiorización ${ }^{4}$ de las mujeres respecto a la salud y la belleza tiene su efecto en la aparente consideración de la selección humana natural sobre la belleza masculina; 4) los hombres frente al arte constituyen la superioridad frente a eventuales excepciones de presencia femenina; 5) la literatura masculina fomenta, por un lado, la pasión de las mujeres por el amor y, por el otro, la participación de los hombres en la guerra; 6) la restricción de la participación de las mujeres en el juego y el deporte, a pesar de que el instinto de juego es común a niños y niñas, las sitúa a ellas (a las mujeres) en una posición inactiva; 7) la ética y la religión actúan como instituciones propulsoras de las virtudes femeninas de las mujeres y las virtudes masculinas de los hombres (aparentemente inalterables en uno u otro sentido) con los argumentos "irrevocables" de la complementariedad social entre ambos grupos de virtudes y el inexcusable poder de la "voluntad divida" para crear hombres y mujeres de forma diferenciada; 8) el prejuicio androcéntrico se instaura en la educación, lo que sitúa a las mujeres en el lugar de la ignorancia, aunque la educación era inicialmente una función ligada a la maternidad;9) la interacción social es la primera condición de la vida humana y es dominada por los hombres; 10) la ley y el gobierno androcéntricos se oponen al sufragio de las mujeres; 11) la capacidad punitiva

4 El concepto "inferiorización" podría definirse como la acción de localizar en un lugar inferior algo que naturalmente no lo es. A la inversa, el concepto "superiorización" podría definirse como la acción de colocar en un lugar superior algo que naturalmente no lo es. es exclusivamente de los hombres; 12) la política androcéntrica se opone a la participación política de las mujeres al considerarlas incapaces; y 13) los hombres ostentan el control absoluto sobre la producción económica y la toma de decisiones sobre la empleabilidad de la misma.

En relación con el binomio "economíamujeres", Gilman (2008 [1898]) sustentó que las reglas políticas y sociales androcéntricas limitan las capacidades intelectuales y productivas de las mujeres, lo que impacta negativamente en el desarrollo humano de la ciudadanía. La autora realiza un análisis económico de la familia, en tanto institución, y sostiene los siguientes argumentos: 1) el trabajo en el hogar es entendido como un deber para las mujeres y no como un labor remunerada $y$, por lo tanto, es necesario profesionalizar la educación de los/as hijos/as y las tareas relativas al funcionamiento del hogar; 2) la consideración de la maternidad como valor económico de intercambio en el matrimonio es falsa y perversa; 3) la distinción sexual entre hombres y mujeres es tan exagerada que se ha llegado a identificar como progreso humano todo aquello que tiene que ver con lo masculino; 4) la "relación sexo-economía" acompaña al individuo desde el momento en el que nace y determina su capacidad de progreso vital; 5) la condición humana es capaz de distinguir como injusta la "relación sexo-economía" establecida socialmente pero necesita tiempo para alterar su propia condición; 6) el matrimonio puede ser considerado un "medio de vida" pero no puede presuponerse un "empleo honesto" porque forma parte del ámbito de la mendicidad económica; 7) los atributos humanos son compatibles con 
las relaciones sexuales pero no con el "sistema sexo-economía" y sus implicaciones para con las relaciones sexuales preestablecidas socialmente; 8) el matrimonio pasa a ser una responsabilidad económica excesiva para los hombres que "deben" proveer al hogar de los bienes materiales necesarios para su funcionamiento; y 9) el casamiento pasa a considerarse como la única vía de sustentabilidad vital a la que las mujeres tienen acceso y, por lo tanto, su preocupación se focaliza en asegurarse un matrimonio que les permita mantener un nivel de vida adecuado a su estatus social.

En la actualidad, los argumentos de Gilman pueden ser criticados tanto por anacrónicos como por la necesidad de localizar sus premisas en un contexto global multicultural regido por diversos sistemas socioeconómicos androcéntricos, más allá del modelo estadounidense al que hacía referencia en sus escritos de finales del siglo XIX y principios del siglo XX. Sin embargo, debe ser reconocida la enorme contribución que supuso su obra para, entonces, considerar sus escritos como pioneros para el surgimiento de la Economía del Género (localizando el foco atencional en el análisis de las consecuencias derivadas de la distribución socioeconómica desigual de poder entre los géneros) y poder hablar ahora de un objeto de estudio histórico.

Tal vez resulte pertinente vincular la descripción de la "relación sexo-economía" propuesta por Gilman (2008 [1898]) para analizar el "androcentrismo", con la concepción del "sistema sexo-género" sugerido por Rubin (1975) para describir el "patriarcado". La adecuación de la coligación de ambos conceptos reside, fundamentalmente, en la necesidad de reconocer la existencia de una constante retroalimentación bidireccional entre ideologías androcéntricas y sistemas patriarcales. Los sistemas necesitan de las ideologías para articular, desde la base, los principios que se quieren modular ideológicamente, mientras que las ideologías requieren de los sistemas para deliberar, desde la base, las estructuras que se quieren materializar.

Desde la antropología y el análisis de los sistemas de parentesco, Rubin (1975) define el "sistema sexo-género" como "el conjunto de disposiciones por el cual una sociedad transforma la sexualidad biológica en productos de la actividad humana y en el cual se satisfacen esas necesidades humanas transformadas"s (Rubin, 1975: 159). Para Rubin (1975), la organización social a través del sexo conlleva tres aspectos esenciales: 1) una organización del sistema de género que tiene como finalidad la eliminación de las semejanzas entre hombres y mujeres para reforzar la necesidad de dependencia mutua basada en una supuesta "complementariedad" entre ambos sexos; 2) una heterosexualidad obligatoria; y 3) demarcaciones sobre la sexualidad femenina.

De la unión de los conceptos propuestos por Rubin y Gilman ("sistema sexo-género" y "relación sexo-economía") quizá pudiera extraerse el término "sistema sexo-género-economía" y definirse como la arquitectura sociopolítica, con base ideológica androcéntrica, que tiene por finalidad compartimentar las contribuciones socioeconómicas del "universo de lo masculino" y el "cosmos de lo femenino", ni de forma idéntica en todas las regiones del mundo 5 Mi traducción, del original en inglés. 
ni de forma obligatoriamente semejante entre todos los miembros de un mismo universo, con grandes perjuicios para el logro del pleno desarrollo humano (principalmente el relativo a las mujeres). También podrían destacarse dos características fundamentales en relación con el "sistema sexo-género-economía": por un lado, el principal regulador de dicho sistema es la distribución de poder entre los géneros respecto el acceso y el control sobre los recursos necesarios para el logro del bienestar y, por el otro, las principales herramientas utilizadas por dicho sistema son estereotipos, prejuicios, creencias, roles y normas idiosincrásicas inherentes a cada sociedad.

En consecuencia, si pudiera considerarse la existencia de un "sistema sexo-género-economía", articulado a escala mundial a través de arquitecturas patriarcales e ideologías androcéntricas, las preguntas de investigación que subyacen en el fondo a los objetivos planteados en el presente artículo, son:

1. ¿Qué características presentan aquellos enfoques que han ayudado a tomar conciencia, en el seno de algunas agencias internacionales, sobre la necesidad de acabar con las políticas orientadas al desarrollo socioeconómico con perfil androcéntrico?

2. ¿Qué papel han representado los feminismos, y los movimientos de mujeres que los conforman, en esa ruptura progresiva del pensamiento androcéntrico en algunas agencias internacionales dedicadas al desarrollo socioeconómico?
Quizá sea pertinente aclarar, en este punto, que el hecho de considerar un "sistema sexo-géneroeconomía" articulado a escala mundial requiere tanto de la necesidad de suponer que dicho sistema se encuentra acoplado por subsistemas desemejantes entre sí que son caracterizados por las idiosincrasias regionales de un mundo global, como de la necesidad de reconocer que el funcionamiento de dicho sistema provoca disfunciones desiguales en el conjunto de las diferentes poblaciones. Sin embargo, hay que añadir que esas disfunciones son analizables, siempre, desde una perspectiva de género $y$, de una forma interseccionada, desde otros puntos de vista, como por ejemplo una óptica cultural. Por lo anterior, es necesario no obviar otras variables estructurales que coparticipan en la arquitectura socioeconómica androcéntrica como lo son el sistema capitalista (con base ideológica clasista), el sistema globalizador (con base ideológica etnocéntrica) o los sistemas esclavistas (con bases ideológicas segregacionistas).

Hay que señalar, también, que el "sistema sexo-género-economía" ha sido analizado de forma crítica, teniendo en consideración la clasificación propuesta por Pérez Orozco (2005): 1) en el ámbito de la Economía de Género (Humphries, 1995), la cual busca la inclusión de las mujeres como sujetos y objetos de estudio de las teorías económicas androcéntricas; 2 ) en el contexto de la Economía Feminista de la Conciliación (Eisenstein, 1979), que procura generar una teoría económica alternativa a las teorías androcéntricas pero tomando en consideración algunos antiguos paradigmas de utilidad; y 3) en el terreno de la Economía Feminista de la Ruptura (Carrasco, 2001), que intenta construir una nueva teoría económica 
rompiendo completamente con los paradigmas económicos androcéntricos existentes.

Por último, en relación con los capítulos que modulan el artículo, se han planteado cuatro apartados para abordar el objeto de estudio: a) examen del punto de vista asistencialista y androcéntrico derivado del "enfoque de bienestar"; b) análisis de la visión economicista emanada del "enfoque de mujeres en el desarrollo", en el contexto del surgimiento del concepto "feminización de la pobreza"; c) estudio de la perspectiva de ruptura con el androcentrismo que suponen el "enfoque de género en el desarrollo" $\mathrm{y}$ el "enfoque de género y desarrollo humano", en el contexto del surgimiento del concepto "desigualdades de género en el desarrollo"; y d) reflexión sobre el devenir de la utilización de la perspectiva de género en el análisis socioeconómico ideado por las agencias internacionales, considerando que la incipiente ruptura con el pensamiento androcéntrico comenzó a ser tenida en cuenta en el plano político-discursivo pero que tiene aún retos pendientes de encarar para su puesta en práctica efectiva.

\section{EL “ENFOQUE DE BIENESTAR”}

Los primeros enfoques y teorías sobre el desarrollo económico adoptados por organismos internacionales como el FMI o el BM, concebidos ambos en 1944, presentaban un claro sesgo androcéntrico e ignoraban el papel de las mujeres en el proceso de desenvolvimiento. Tal es el caso, por ejemplo, de la "teoría económica de la modernización” (Lewis,

6 Moser (1993) fue pionera en la sistematización de los siguientes enfoques: "enfoque de bienestar", "enfoque de mujeres en el desarrollo" y "enfoque de género en el desarrollo".
1969), que sostiene que la diferenciación en el empobrecimiento de las diferentes áreas geográficas del mundo puede explicarse en función de los distintos niveles de desarrollo tecnológico de las sociedades y relega a las mujeres al ámbito doméstico. En este sentido, el contexto privado carece de valor en la ecuación del crecimiento económico, es decir, todo aquel trabajo mercantilmente no cuantificable no es considerado como trabajo productivo y, por lo tanto, no es tenido en cuenta para el cálculo económico mundial.

En consecuencia, entre los años 1950 y 1960, surge, como resultado de la aplicación de dicha "teoría económica de la modernización", el "enfoque de bienestar" (Hernández, 1999), que toma a las mujeres como merecedoras o receptoras pasivas de las acciones de desarrollo ante su posición de madres, cuidadoras y vulnerables. Dicho enfoque enfatiza el rol reproductivo de las mujeres considerando la necesidad de orientar los esfuerzos del desarrollo en hacer que ellas (las mujeres) puedan llegar a ser "madres más sanas" porque esto repercutirá positivamente en el desarrollo de sus hijos/as. Por lo tanto, dicho enfoque orienta las estrategias de desarrollo en relación con algunas necesidades específicas de las mujeres más empobrecidas, en torno a dos tipos de acciones: 1) ayuda alimentaria y lucha contra la malnutrición ${ }^{7}$ y 2) planificación familiar y la salud materno-infantil. ${ }^{8}$ Este enfoque de desarrollo

7 Una de las iniciativas creadas en el contexto de la acción "ayuda alimentaria y lucha contra la malnutrición" fue la articulación del conjunto de expertos llamado "Grupo Asesor de la Proteína", creado en 1955, que fue integrado por FAO, UNICEF y OMS (Giles-Vernick y Webb, 2013). 8 La acción "planificación familiar y salud materno-infantil" ha sido liderada, históricamente, por agencias como UNICEF 
se encuentra auspiciado por organismos surgidos, también, a partir de 1940, como la Organización de las Naciones Unidas para la Alimentación y la Agricultura (FAO) — creada en 1943 —; el Fondo de Naciones Unidas para la Infancia (UNICEF) — creado en 1946 - y la Organización Mundial de la Salud (OMS) —creada en 1948.

Por último, el carácter androcéntrico del "enfoque de bienestar" reside en dos aspectos heredados de la "teoría económica de la modernización": 1) la consideración de que aquello que económicamente no tiene precio monetario no cuenta para la economía y 2) el no reconocimiento de las relaciones de género como relaciones con significación económica, es decir, el no reconocimiento de la existencia de un "sistema sexo-género-economía" que perjudica el desarrollo integral, principalmente, de las mujeres.

\section{SURGIMIENTO DEL CONCEPTO “FEMINIZACIÓN} DE LA POBREZA": EL "ENFOQUE DE MUJERES EN EL DESARROLLO"

Se consideran aquí algunos diagnósticos sobre la "feminización de la pobreza" y se describen las soluciones primigenias para enmendar dicho fenómeno desde la adopción del “enfoque de mujeres en el desarrollo". Es necesario apreciar que la conceptualización de la "feminización de la pobreza" se inserta en un contexto global en el que, atendiendo a las recomendaciones de la Organización para la Cooperación y el Desarrollo Económico (OECD, 1984), se consideran "personas empobrecidas" a

y OMS, que en 1978 organizaron la llamada "International Conference on Primary Health Care", marcando la "salud materno-infantil" como uno de sus ejes de actuación prioritario (Kawachi y Wamala, 2007). aquellos individuos, familias o grupos de personas a quienes las limitaciones de recursos (culturales, materiales y sociales) les excluye del tipo de vida mínimo considerado aceptable en el Estado en que residen. Asimismo, el fenómeno de la "feminización de la pobreza" se enmarca, en una tentativa de medir el número de personas empobrecidas en el mundo, a través del parámetro de la pobreza absoluta, en una línea internacional marcada por el BM (World Bank, 1990), teniendo en cuenta como puntos de cohortes, por un lado, el acceso a dos dólares al día por parte de cada uno de los habitantes del mundo (para identificar la pobreza) y, por otro lado, el acceso a menos de un dólar al día por parte de cada uno de los conciudadanos del mundo (para identificar la pobreza extrema).

\section{Diagnósticos sobre la "feminización de la pobreza"}

Uno de los primeros fenómenos sujeto a un análisis desde la perspectiva de género, en el contexto del desarrollo socioeconómico, fue el avance de la "feminización de la pobreza", fenómeno que viene reflejado por cifras como, por ejemplo, que el $70 \%$ de las personas empobrecidas en el mundo son mujeres, o que dos tercios de los 900 millones de personas analfabetas en el mundo son mujeres (García-Mina, Carrasco, 2004).

Inicialmente, el principal eje identificado en relación con la "feminización de la pobreza" fue la división sexual del trabajo. Para ello se tuvo en cuenta que dicha división provoca una atribución de funciones sociales que se ha postulado, en la mayor parte de las sociedades productoras de bienes y servicios, con la asignación a las mujeres 
del rol de trabajo reproductivo (habitualmente no remunerado) y la asignación a los hombres del rol de trabajo productivo (habitualmente remunerado). La principal consecuencia de esta asignación de roles de género es el desigual reparto de bienes entre hombres y mujeres y la consecuente dependencia económica de las mujeres con respecto a los hombres en un mundo principalmente monetario y globalizado(r). Una dependencia económica que, por otro lado, limita (cuando no impide) el acceso y el control sobre los recursos destinados a servicios básicos vitales como la educación, la alimentación o la salud.

Cabe reflexionar, sin embargo, en torno a cuatro cuestiones fundamentales vinculadas a la "feminización de la pobreza": 1) el origen del reparto social del trabajo en función del sexo; 2) la imposibilidad de generalizar el reparto social del trabajo en función del sexo a todas las sociedades o circunstancias vitales; 3 ) las características por las que no son considerados como productivos ciertos trabajos que habitualmente realizan las mujeres; y 4) el debate del concepto mismo de "feminización de la pobreza".

- $\quad$ El origen del reparto social del trabajo en función del sexo

Existe un consenso académico en relación con la consideración de que la división sexual del trabajo viene determinada por un largo proceso histórico occidental, que se afianza a partir de la revolución industrial pero que puede encontrar su origen en la era preindustrial. En este complejo y largo proceso, las familias abandonan el campo para trabajar en las fábricas de las ciudades, las familias extensas se convierten en familias nucleares y, llegados a este punto, se establece socialmente, como si fuesen funciones naturales, que los hombres salgan de las casas a trabajar en el espacio exterior y las mujeres cuiden del mantenimiento de los miembros de la familia en el espacio privado. A este cambio social se le denomina "nueva organización social capitalista" (Appleby, 1984). De acuerdo con Boserup, una de las causas que podría explicar la reclusión de las mujeres en la esfera privada podría ser la de que "cuando el desarrollo económico hace que un número elevado de hombres salga de los sectores agrícolas y de servicios y comercio tradicional, el consiguiente traslado de las familias del campo a la ciudad puede provocar que las mujeres dejen también de trabajar en estos sectores sin que se les ofrezcan oportunidades en el sector moderno" (Boserup, 1993 [1970]: 222).

En este sentido, y de acuerdo con la hipótesis formulada por Engels (2001 [1884]) en sus investigaciones sobre el origen de la propiedad privada, el éxodo rural a las ciudades supone un cambio en el orden social que, efectivamente, propicia que las mujeres queden recluidas en sus hogares como símbolo del progreso masculino y surgimiento de las clases medias.

Mies (1998) fundamenta su teoría sobre el origen capitalista del reparto social del trabajo en función del sexo para defender, desde el "feminismo socialista", que el origen de la imposición del rol de sumisión de las mujeres no se basa en causas biológicas, ni siquiera en causas relacionadas con la conservación de tradiciones, sino en causas sociales relacionadas con la producción de bienes. Es por ello que - 
argumenta-, la subordinación de las mujeres estaría relacionada con la aparición de la propiedad privada. Además, según la autora, el capitalismo y el patriarcado se asocian en la tarea de oprimir a las mujeres a través de la atribución de roles diferenciados entre hombres y mujeres, no igualmente remunerados ni igualmente considerados en la escala social.

Por su parte, Hartman (1994) sostiene, también desde el "feminismo socialista", que el origen de la división sexual de trabajo y la jerarquización social derivada de la misma se localiza en la era preindustrial y es anterior, por lo tanto, al surgimiento del capitalismo. Según Hartman, dicha jerarquización pudo suponer el origen del patriarcado $y$, en consecuencia, el inicio de la subordinación femenina frente a la masculina, a través de la aplicación de técnicas jerárquicas de organización y control utilizadas por los hombres.

Davis (2005 [1981]), basada en el "feminismo de la interseccionalidad" y a partir de la perspectiva de la división genérica de la sociedad, teoriza sobre la configuración de la división sexual del trabajo teniendo en cuenta, además, aspectos como el racismo (con su máxima expresión en la esclavitud) y el clasismo (derivado del capitalismo). La autora apunta que la división del trabajo entre los sexos no fue siempre tan rigurosa $\mathrm{y}$, en ocasiones, los hombres pudieron haber trabajado en las cabañas y las mujeres pudieron haberse ocupado del huerto y, quizá, haber participado en la caza. Asimismo, Davis señala que si bien el lugar de las mujeres en la era preindustrial habría estado cerca del hogar, durante dicha era la propia economía se habría centrado en la vivienda y en el terreno agrícola aledaño. Finalmente, la autora propone que la segregación genérica del trabajo no ha sido determinada por un único patrón dictaminado por la industrialización y pone como ejemplo las experiencias de las mujeres esclavas, ya que sus vivencias durante la esclavitud les debieron afectar profundamente teniendo en cuenta que las demandas de sus "amos" les exigían ser igual de "masculinas" que los hombres en el cumplimiento de su trabajo esclavo.

Asimismo, tal y como argumenta Rubin (1975), es necesario indicar, por un lado, que el nuevo orden social capitalista se apoya en ideas anteriores al surgimiento del propio capitalismo para reorganizar "el mundo de lo femenino" y el "mundo de lo masculino" en torno al sistema de producción de capitales. Y, por otro lado, es imprescindible aclarar que el capitalismo no consigue explicar la ingente cantidad de injusticias y atrocidades cometidas en contra de las mujeres (por el hecho de nacer "mujeres") en la era preindustrial, continuadas en la era industrial, y tampoco consigue explicar por qué son generalmente las mujeres las que hacen el trabajo doméstico, en lugar de los hombres, en sociedades preindustriales e industriales. Por ese motivo, según la autora, las desigualdades de género no sólo pueden explicarse en función del capitalismo sino también en función de la configuración del "sistema sexo-género".

- La imposibilidad de generalizar el reparto social del trabajo en función del sexo a todas las sociedades o circunstancias vitales 
Cabe preguntarse en qué medida los pueblos del mundo se han adaptado, o no, a esa nueva organización social capitalista obteniendo como consecuencia la reclusión de las mujeres en el espacio privado. Para ello es necesario tener en cuenta que las mujeres en los entornos rurales participaban, y participan, activamente en la producción agrícola y ganadera, así como en los beneficios económicos que esta actividad reporta, aunque exista una división sexual del trabajo que les vincule, además, al cuidado de la familia. De hecho, se estima que las mujeres constituyen el $43 \%$ de la mano de obra agrícola en los "países en desarrollo" (Food and Agriculture Organization of the United Nations, 2011).

Además, podría presuponerse que no todas las culturas han accedido a la industrialización en la misma medida y, por lo tanto, que el cambio social es significativamente distinto en cada una de las sociedades que se pueden analizar, dependiendo de su nivel de industrialización y de conservación de la cultura "tradicional". Aun así, como punto de inflexión puede decirse, en relación con la división sexual del trabajo, como señala Amorós (2007), que a medida que avanza el desarrollo tecnológico en las sociedades agrarias se va afianzando la segregación de los sexos.

De igual modo, en los contextos urbanos, la industrialización también supuso la incorporación de las mujeres, principalmente de clases sociales con menores recursos, al mercado laboral en determinadas tareas como el servicio doméstico o el trabajo como obreras en las fábricas; esto es, la revolución industrial supone para las mujeres de clases sociales desfavorecidas asumir trabajo extra-doméstico, sin que ello signifique el abandono del correspondiente trabajo doméstico (Amorós, 2007). Por lo tanto, la adaptación social a la nueva organización capitalista no puede generalizarse a las clases sociales con menores recursos, o situaciones de hogares monoparentales encabezados por mujeres, porque en estos casos las mujeres urbanas participaban, y participan, activamente en el trabajo productivo extradoméstico para el mantenimiento económico de las familias.

Desde el "feminismo postmoderno", Mohanty (1991) formula su teoría sobre el estudio de la división sexual del trabajo basándose en la crítica sobre la "metodología del universalismo". Para la autora, existe un sesgo etnocéntrico determinado por el reduccionismo cultural y por el intento de universalizar las realidades locales, en el análisis realizado por las "feministas occidentales" sobre la división sexual del trabajo. Por un lado, dicho intento de universalización pudiera venir determinado, según la autora, por la tentativa de llevar a cabo un análisis sobre un proceso universal de opresión de las mujeres, que puede no ser homogéneo a la hora de estudiar los contextos de los "países en desarrollo". Por otro lado, dicho intento de universalización origina proyecciones etnocéntricas sobre, por ejemplo, las concepciones vertidas sobre las "mujeres africanas", quienes son comúnmente consideradas vulnerables y agentes pasivas de su desarrollo.

- Las características por las que no son considerados como productivos ciertos trabajos que habitualmente realizan las mujeres

Resulta difícil calcular la aportación del trabajo de las mujeres a la economía global por la desconsideración del trabajo informal y el 
trabajo doméstico en la ecuación del crecimiento económico de un determinado país; es decir, la mayor parte del trabajo realizado por las mujeres no se le define como productivo en cuanto no es considerado mercantilmente cuantificable.

En este sentido, la "teoría de los sistemas mundiales" de Ward y Pyle (1995) pone de manifiesto que el sistema económico mundial no podrá comprenderse si no son considerados y cuantificados el trabajo informal y el trabajo en el hogar, además de tomar en cuenta las contribuciones de las mujeres al sistema económico mundial de forma particular y no sólo como categoría global "trabajadores".

En el contexto de sus investigaciones realizadas sobre el trabajo no remunerado en la economía global, Durán (2012) pone de manifiesto la dedicación casi exclusiva por parte de las mujeres con relación al trabajo no remunerado en los hogares. ${ }^{9} \mathrm{La}$ autora señala que también son las mujeres las que ocupan principalmente los trabajos considerados informales en los "países en desarrollo", como estrategia para combatir la pobreza en sus familias, y advierte de la vulnerabilidad de las jóvenes porque son las niñas quienes trabajan a más temprana edad con respecto a los niños, cobran menos por el mismo trabajo y lo hacen durante más horas. Durán precisa que las mujeres dedican más tiempo al cuidado tanto de los/ as niños/as como de otras personas dependientes (incluidas aquellas con discapacidad y enfermos/ as y ancianos/as con necesidades atencionales).

9 El trabajo en el hogar requiere una mayor dedicación en las viviendas que no se encuentran dotadas, por ejemplo, de acceso a agua corriente, de servicios de saneamiento o de electrodomésticos que faciliten su ejecución.
Por último, la autora expone algunos ejemplos en relación con el empleo del tiempo, poco tenidos en cuenta por el sistema económico global, tales como la dedicación a la preparación de la muerte y la memoria de la persona difunta, considerando estudios realizados en Zimbabue, Sudáfrica o Uganda.

- La "feminización de la pobreza": un concepto de debate

El concepto "feminización de la pobreza", que supone la presencia mayoritaria de mujeres entre las personas consideradas empobrecidas, ha sido puesto a debate en los últimos años por dos razones fundamentales: 1) como señalan Medeiros y Costa (2008), la enorme carga significativa inicial del concepto "feminización de la pobreza" no ha sido acompañada suficientemente de estudios científicos, y 2) como señala Chant (2004), el concepto "feminización de la pobreza" ha sido asociado de manera insistente al concepto "hogares con jefatura femenina", como si la pobreza tuviera una relación más directa con las características civiles (marital, soltería, viudez, etcétera) de quien encabeza un determinado hogar y menos directa con el contexto socioeconómico y político donde se sitúa dicho hogar.

Así, en los últimos años, el foco de atención sobre el concepto "feminización de la pobreza" ha sido desviado hacia otras variantes como, por ejemplo, la "feminización de la supervivencia" (Cobo, 2007), que supone la presencia mayoritaria de mujeres en empleos de carácter gratuito (imprescindibles para la sostenibilidad social), mal pagados (necesarios para el avance del capitalismo y la globalización) y en 
tareas esclavizadoras relacionadas, principalmente, con la explotación sexual.

Siguiendo a Cobo (2007), la globalización es un proceso histórico socioeconómico y cultural asociado a la modernización y a la expansión del capitalismo a través de las políticas neoliberales. Como señala la autora, dicho proceso tiene, a la vez, una cara positiva, que ofrece la posibilidad de comunicación intercultural a través del desarrollo tecnológico y una cara negativa, que supone el crecimiento económico como fin en sí mismo y sin importar los medios para su consecución, aunque éstos impliquen la imposición de modas globales. Según la autora, es imprescindible una visión feminista sobre la globalización para comprender fenómenos como, por ejemplo, las migraciones vinculadas a la prostitución, el trabajo femenino en las maquilas, la informalización del trabajo realizado por las mujeres, etcétera. Fenómenos que, por otro lado, son la estructura que sustenta la "feminización de la supervivencia". En ese sentido, las políticas neoliberales enfatizan la "feminización de la supervivencia" a través de la adjudicación, principalmente a las mujeres, de mayor cantidad de trabajo gratuito, mayor cantidad de trabajo mal pagado y un peso específico en trabajos relativos a la explotación sexual.

Soluciones primigenias frente a la "feminización de la pobreza": el "enfoque de mujeres en el desarrollo"

Las soluciones primigenias abordadas frente a la "feminización de la pobreza" en el contexto del desarrollo socioeconómico orquestado por algunas agencias internacionales vienen determinadas fundamentalmente por una óptica economicista dada por el "enfoque de mujeres en el desarrollo".

Apartir de 1970 existe una ruptura progresiva del pensamiento único neoliberal economicista motivada por el "enfoque de las necesidades básicas" (International Labour Office, 1977), que considera insuficiente la medición del desarrollo únicamente desde la consideración del crecimiento económico porque, por un lado, el crecimiento del Producto Interno Bruto (PIB) no es garantía sistemática del desarrollo de un determinado país y, por el otro, el desarrollo medido únicamente desde el crecimiento económico no desvela información relacionada con dimensiones tan importantes como el desempleo, la pobreza o la desigualdad, entre otros. Dicho enfoque presenta los siguientes grupos de necesidades básicas propositivas para ser alcanzadas: 1) requerimientos mínimos para el consumo familiar y personal [alimento, vivienda, etcétera]; 2) acceso a servicios esenciales [salud, transporte, educación, saneamiento, agua potable, etcétera]; 3) posesión de un trabajo digno; y 4) necesidades superiores [entorno saludable y humano, participación en la toma de decisiones, consecución de libertades individuales, etcétera].

También a partir de 1970 surgen enfoques que se pronuncian en torno al concepto "desarrollo" desde una incipiente perspectiva de género. Se trata entonces de romper el androcentrismo en las ciencias económicas y hacer constatar las desigualdades existentes entre hombres y mujeres (asimetrías que parecen ir en aumento a medida que los pueblos se desarrollan). Hay un consenso académico a la hora de considerar que fue Boserup (1993 [1970]) la encargada de 
dar el primer paso para argumentar por qué es importante tener en cuenta la variable "género" en el análisis socioeconómico para ofrecer datos y explicaciones sobre las consecuencias de la ignorancia de la óptica de género en el desarrollo económico. Para Boserup (1993 [1970]) existen dos aspectos clave en el análisis económico visto desde la perspectiva de género: por un lado, el oscurantismo sobre la posición de las mujeres en el desarrollo económico origina su desubicación en el sistema productivo capitalista; $y$, por el otro, las nuevas dinámicas socioculturales establecidas como consecuencia del éxodo rural de las poblaciones hacia las ciudades trae consigo la descontextualización de las mujeres en aquellos trabajos relacionados con la modernidad.

Las razones fundamentales identificadas sobre el aumento de la desigualdad de género en función del desarrollo de los pueblos, según el estudio de Maguire, son ocho:

(1) Las tradiciones, las actitudes y los prejuicios en contra de la participación de las mujeres; (2) Barreras legales; (3) Limitado acceso y uso de la educación formal, lo que resulta en altas tasas de analfabetismo femenino; (4) El tiempo empleado por las mujeres en las tareas domésticas; (5) Las condiciones de acceso a la tierra, al crédito, a la maquinaria agrícola moderna, a las técnicas y servicios de extensión; (6) La carga para la salud derivada de los embarazos frecuentes y la desnutrición; (7) Debilidad de la posición tradicional otorgada a las mujeres como socias contribuyentes económicamente y (8) Inadecuadas investigaciones e información sobre las mujeres que limita la capacidad de los planificadores del desarrollo para crear proyectos de interés para las mujeres ${ }^{10}$ (Maguire, 1984: 13).

Así surge, a partir de 1970, el "enfoque de mujeres en el desarrollo", término acuñado por el Comité de Mujeres de la Sociedad para el Desarrollo Internacional ("Women's Comittee of the Society for International Development") que empezó a conocerse como "Mujeres en el Desarrollo" ("Women in Development"). Este enfoque se fundamenta en los paradigmas del "feminismo liberal" (Staudt, 1986) y centra sus esfuerzos en el análisis de los roles de género en las sociedades y en el intento de incluir a las mujeres de forma activa en el proceso de desarrollo económico, enfatizando el rol productivo de las mismas sin que este propósito suponga la transformación de las estructuras sociales existentes. Además, dicho enfoque se encuentra orientado a la satisfacción de las necesidades básicas de las mujeres más empobrecidas, a través de su incorporación al mercado de trabajo productivo, y utiliza tres estrategias para la integración de las mujeres en el desarrollo: "estrategia de igualdad formal", "estrategia de antipobreza" y "estrategia de eficacia".

Por un lado, la "estrategia de igualdad formal"11 (Moser, 1993), curtida en el seno de las conferencias internacionales sobre las mujeres organizadas por la ONU entre principios de la década

10 Mi traducción, del original en inglés.

$11 \mathrm{La}$ "estrategia de igualdad formal" fue identificada por Moser (1993) como "estrategia de equidad". Se ha eludido utilizar el término "equidad", en este punto, para no confundir dicha "estrategia de igualdad formal", o "estrategia de equidad" según Moser (1993), con el principio fundamental de "equidad de género" que se encuentra inserto en los fundamentos del "enfoque de género en el desarrollo". 
de 1970 y finales de la década de 1980 (UN, 1976; UN, 1980; UN, 1986), se encuentra orientada a la reforma de leyes, a los cambios institucionales y a la concienciación de la sociedad, al tiempo que persigue un estatus igualitario entre hombres y mujeres en el ámbito formal. Esta estrategia tuvo como objetivo fundamental cambiar el prisma sobre el bienestar de las mujeres en el desarrollo para pasar a tratar la igualdad de las mujeres en el desarrollo.

Por otro lado, la "estrategia de antipobreza" (Moser, 1993), que emerge a mediados de 1970, se encuentra orquestada, principalmente, por el Banco Mundial y busca la satisfacción de necesidades básicas de las familias a través de la incorporación de las mujeres al sistema de producción de capitales.

En un informe realizado en 1979, el BM (World Bank, 1979a) presenta un diagnóstico sobre el trabajo ejecutado por parte de las mujeres y advierte sobre la dificultad de visibilizar el trabajo que realizan, a pesar de que constituyen el $70 \%$ de la fuerza de trabajo agrícola. El informe también señala que los siguientes factores se refuerzan entre sí para mantener a las mujeres en la parte inferior de la escala económico-productiva: 1) realizan trabajos que requieren escasa formación; 2) realizan trabajos de baja productividad y de bajos salarios; y 3) ocupan trabajos en el sector informal.

Por lo tanto, el diagnóstico para la incorporación de las mujeres al sistema productivo, como base fundamental de la "estrategia de antipobreza", es la constatación de que son las menos remuneradas en el sistema de producción y que esto repercute en el mantenimiento del empobrecimiento de los hogares más desfavorecidos.
Los cuatro factores fundamentales que se argumentan para la aplicación de la "estrategia de antipobreza", centrada en la incorporación de las mujeres al sistema productivo, según señala Sen (1991), son: 1) las mujeres pueden contar con beneficios económicos a través del trabajo productivo fuera de los hogares; 2) el trabajo productivo mejorará su posición social; 3) el trabajo productivo les aporta condiciones de seguridad socio-laboral; y 4) las mujeres obtendrán nuevas experiencias a través de la ejecución de trabajos productivos a partir de la interacción en el espacio público.

A los cuatro factores anteriores, sin embargo, habría que añadir que se constató que las mujeres que trabajaban fuera de los hogares, además de hacerlo simultáneamente dentro de los hogares, no eran remuneradas con la suficiente cantidad y calidad como para salir de la situación de pobreza (World Bank, 1979a). Asimismo, el BM (World Bank, 1979b) concluía en otro de sus informes que la disminución de la natalidad, como una de las estrategias para combatir la pobreza, se encuentra influenciada, entre otras cuestiones, por la efectividad de los programas de planificación familiar y por la incorporación de las mujeres a la fuerza de trabajo productiva.

Finalmente, la "estrategia de eficacia" (Moser, 1993) emerge a partir de 1980 y se fundamenta en la idea de que el desarrollo sería más eficaz si se tuviera en cuenta el trabajo que realizan de forma habitual las mujeres, es decir, si se tuvieran en cuenta los roles desempeñados tradicionalmente por las mujeres. La "estrategia de eficacia" es llevada a cabo también por el BM, 
como lo muestran las siguientes conclusiones derivadas de un diagnóstico sobre el trabajo realizado por parte de las mujeres en algunas regiones de África (World Bank, 1989): 1) las mujeres africanas son las encargadas de coordinar el suministro de comida, nutrición, agua, salud, educación y la planificación familiar; 2) son las guardianas del bienestar de sus hijos/as; 3) siempre han estado activas, en términos de trabajo productivo, en relación a la agricultura, el comercio y otras actividades económicas; 4) la sobrecarga de trabajo productivo para las mujeres pone en peligro el bienestar de la familia; 5) la "modernización" ha cambiado el equilibrio de ventajas en relación con las mujeres, teniendo en cuenta que el marco legal y los sectores productores de servicio desarrollados en las naciones africanas no han beneficiado a las condiciones de trabajo de las mujeres [ellas tienen serios problemas para acceder al crédito y dificultades para acceder a las nuevas tecnologías; las mujeres han perdido su derecho tradicional a hacer uso y disfrute de la tierra teniendo en cuenta que las nuevas adjudicaciones de las tierras han sido hechas a nombre de los hombres de la familia y que el sistema de agricultura de extensión tampoco beneficia a las mujeres, a pesar de que son importantes productoras de alimentos]; 6) las mujeres están menos preparadas con respecto a los hombres para afrontar las nuevas oportunidades en las economías africanas; 7) el trabajo no remunerado realizado por las mujeres ha aumentado; y 8) en relación con la industria, las mujeres han ocupado espacios de producción en el sector informal y esto significa que su capacidad para obtener menores ingresos perjudica su habilidad para proveer el bienestar de sus hijos/as.

Consecuentemente, el BM advierte de la necesidad de aumentar la eficacia y la eficiencia de las acciones de desarrollo, en términos de recursos humanos, para no sobrecargar a las mujeres en relación con la asunción de la ejecución de los trabajos realizados tradicionalmente por ellas, amén de los trabajos que pretenden que sean asumidos también por ellas a través de las acciones de desarrollo productivas.

Son tres las críticas fundamentales que recibe el "enfoque de mujeres en el desarrollo", según señala Rathgeber (1989): 1) es adoptado por algunas agencias internacionales integrando el concepto "desarrollo" desde el punto de vista tradicional de la "teoría de la modernización", es decir, se hace necesario continuar produciendo capital y para ello es necesario incluir a las mujeres en el sistema de producción de capitales; 2) acepta las estructuras sociales preexistentes sin cuestionamiento alguno; y 3) pone atención exclusiva a los aspectos productivos del trabajo realizado por las mujeres, ignorando otras funciones sociales efectuadas habitualmente por ellas.

Hay una cuarta crítica vertida desde el "feminismo socialista" (Benería, Sen, 1983) que recrimina que no se considere la importancia del papel que desempeñan las clases sociales en el desarrollo; para dicho feminismo, el papel de las mujeres en el desarrollo debe explicarse a partir de la conexión existente entre las desigualdades de género y las desigualdades de clases sociales, porque son las mujeres más empobrecidas 
las más oprimidas por el capitalismo. En este sentido, el hecho de que la "estrategia de antipobreza" focalice la atención en las mujeres más empobrecidas, significa que pretende que las mujeres más empobrecidas entren a formar parte del sistema de capitales sin tener en cuenta que, quizá, una de las causas de la pobreza que sufren dichas mujeres sea el funcionamiento del propio sistema al que se les pretende incorporar.

Del mismo modo, existe una quinta crítica, realizada desde el "feminismo postmoderno" (Mohanty, 1991), que apuesta por abandonar el intento de universalismo de la modernización y valorizar las diferencias en el desarrollo para no caer en la tentación de imponer un "feminismo occidental" (una nueva colonización) ante el análisis de realidades diversas.

Es necesario indicar que el "enfoque de mujeres en el desarrollo" ("women in development approach") coexiste coetáneamente con el "enfoque de mujeres y desarrollo" ("women and development approach"), aun cuando este último dejó de centrarse exclusivamente en las estrategias para la integración de las mujeres en el desarrollo económico. En este sentido, el "enfoque de mujeres y desarrollo" se posicionó en el ámbito académico y el "enfoque de mujeres en el desarrollo" se localizó en el ámbito de actuación de algunas agencias internacionales a través de su articulación mediante las estrategias políticas mencionadas (igualdad formal, antipobreza y eficacia).

El "enfoque de mujeres en el desarrollo" pudo suponer el primer paso para iniciar la ruptura con el pensamiento androcéntrico operante en las agencias internacionales dedicadas al desarrollo socioeconómico más influyentes a través del reconocimiento de la existencia de un "sistema sexogénero-economía" que perjudica, principalmente, al desarrollo vital de las mujeres y que parece afianzarse a medida que los pueblos se desarrollan. Sin embargo, las soluciones abordadas por el "enfoque de mujeres en el desarrollo" para afrontar las asimetrías en el desarrollo de hombres y mujeres continuaron presentando un perfil androcéntrico porque carecieron de propuestas vinculadas a la trasformación de las relaciones de poder que dan significado a ese "sistema sexo-género-economía". Es decir, las soluciones planteadas desde dicho enfoque fueron androcéntricas en cuanto apostaron por la inclusión de las mujeres (como añadido) a un sistema económico, esencialmente androcéntrico, sin previa discusión para su modificación sustancial tanto ideológica como estructuralmente. De esta manera, el "enfoque de mujeres en el desarrollo" estuvo lejos de llegar a considerar que el "sistema sexo-género-economía" fuera el origen de las asimetrías en el desarrollo de hombres y mujeres y se aproximó a considerar que el origen del problema de la asimetría de género en el desarrollo económico se encontraba en el papel que las mujeres presentaban en dicho sistema.

Por último, teniendo en consideración la clasificación realizada por Pérez Orozco (2005), podría decirse que "el enfoque de mujeres en el desarrollo" se encuentra inserto en el ámbito del desarrollo académico de la Economía del Género (Humphries, 1995), que busca la inclusión de las mujeres como sujeto y objeto de estudio de las teorías económicas androcéntricas pensando en combatir, de esta forma particular, el androcentrismo. 
SURGIMIENTO DEL CONCEPTO

"DESIGUALDADES DE GÉNERO

\section{EN EL DESARROLLO”: EL “ENFOQUE}

DE GÉNERO EN EL DESARROLLO"

Y EL "ENFOQUE DE GÉNERO

\section{Y DESARROLLO HUMANO"}

A continuación se aborda el cambio acontecido en relación con la mudanza de prisma sobre el análisis de la "feminización de la pobreza" para llegar a examinar las "desigualdades de género en el desarrollo". El fenómeno de la "feminización de la pobreza" localiza el foco atencional sobre las mujeres más empobrecidas mientras que, por el contrario, el fenómeno de las "desigualdades de género en el desarrollo" se presupone global y también afecta, indiscutiblemente, a las mujeres que no se encuentran entre las más empobrecidas. Asimismo, se tendrán en cuenta las características del "enfoque de género en el desarrollo" y el "enfoque de género y desarrollo humano" como paradigmas que intentan materializar el cambio de óptica en el nuevo análisis.

Propuestas para el análisis de las "desigualdades de género en el desarrollo": el "enfoque de género en el desarrollo" y el "enfoque de género $y$ desarrollo humano"

A partir de 1980 surge el "enfoque de las capacidades básicas" que considera las necesidades elementales como una parte de las "capacidades humanas", es decir, como una parte del proceso de expansión de las libertades de las personas y sin que dichas necesidades básicas sean una condición suficiente para alcanzar el pleno bienestar de los seres humanos; en otras palabras, sin que dichas necesidades elementales sean una condición suficiente para alcanzar lo que Sen (1985) denomina la "agencia personal del individuo". Dicho "enfoque de las capacidades básicas" fue instrumentalizado por el Programa de Naciones Unidas para el Desarrollo (PNUD) a través del concepto "desarrollo humano", definido como el "proceso mediante el cual se amplían las oportunidades de los individuos, las más importantes de las cuales son una vida prolongada y saludable, acceso a la educación y el disfrute de un nivel de vida decente. Otras oportunidades incluyen la libertad política, la garantía de los derechos humanos y el respeto a sí mismo [...]" (PNUD, 1990: 33).

Frente a esta forma de concebir el desarrollo de forma global, se presentan, en paralelo, dos novedosas - y complementarias - formas de articular la perspectiva de género en función de dicho desarrollo: por un lado, el "enfoque de género en el desarrollo", que ha sido asumido por algunas agencias internacionales dedicadas al desarrollo socioeconómico en forma de estrategias enfocadas a determinados objetivos y, por el otro, el "enfoque de género y desarrollo humano", que ha sido asumido por algunos ámbitos academicistas con la finalidad de estudiar las casuísticas que fundamentan las desigualdades de género en el camino del desenvolvimiento socioeconómico.

- $\quad$ El enfoque de género en el desarrollo A partir de 1980 surge el "enfoque de género y desarrollo" ("gender and development approach") de la mano del "feminismo socialista" (Sen y Grow, 1987), que identifica en la construcción social de la 
producción y la reproducción la base de la opresión de las mujeres y considera que el patriarcado actúa dentro y fuera de las clases sociales para oprimir a las mujeres. El "enfoque de género y desarrollo" surgió en el seno de la red feminista de trabajo "Development Alternatives with Women for a New Era" (DAWN), fundada en el año 1984, y tiene en cuenta el triple rol ${ }^{12}$ desempeñado por las mujeres en el desarrollo: reproductivo, productivo y gestión del trabajo comunitario.

De forma paralela al "enfoque de género y desarrollo" surgió el "enfoque de género en el desarrollo" (Whitehead, 2006 [1979]), que fundamenta el concepto de subordinación sufrida por parte de las mujeres en el contexto del desarrollo a razón del mantenimiento de las estructuras del patriarcado y, por lo tanto, a razón de la acción de opresión ejercida por parte de los hombres sobre las mujeres.

El "enfoque de género en el desarrollo" ("gender in development approach") ha sido asumido paulatinamente por el discurso de algunas agencias internacionales para el desarrollo, a través del "feminismo oficial", tomando en cuenta el siguiente principio: "las relaciones de poder y subordinación entre hombres y mujeres de cada

12 Moser (1993) acuñó el concepto "triple rol de las mujeres en el desarrollo" definiéndolo en los siguientes términos: 1) el rol reproductivo - comprende el trabajo de reproducción biológica, la ejecución de las tareas del hogar y el trabajo de reproducción social del orden genérico-;2) el rol productivo - comprende el trabajo realizado en el sector formal e informal y el trabajo con retribución dineraria o con compensación en especies-, y 3) el rol comunitario - comprende el trabajo voluntario realizado en el tiempo libre que tiene como objetivo abastecer a la comunidad de determinados servicios relacionados con la educación, los cuidados para la salud, etcétera. contexto cultural e histórico concreto definen la diferente condición de las mujeres y los hombres en cada sociedad" (PNUD, 1995:116).

Las estrategias utilizadas por el "enfoque de género en el desarrollo" son tres: "empoderamiento", "transversalización" y "equidad". Por un lado, la "estrategia de empoderamiento" comenzó a ser utilizada por el grupo DAWN, que la consideró una estrategia individual y colectiva concebida para transformar las relaciones de poder establecidas socialmente entre hombres y mujeres y modificar las relaciones de subordinación cambiando la posición ${ }^{13}$ de las mujeres en la sociedad. Dicha estrategia, que hace alusión a la necesidad de facilitar el acceso al poder y las esferas de decisión por parte de las mujeres, comenzó a ser utilizada, con mayor intensidad, por algunas agencias internacionales, principalmente en el plano discursivo, a partir de la "Conferencia Internacional sobre Población y Desarrollo" (ONU, 1995) y la "Cuarta Conferencia Mundial sobre la Mujer" (ONU, 1996).

El concepto "empoderamiento" tiene su origen en la metodología para la educación popular propuesta por Freire (2009 [1965]), quien equipara la educación con la libertad. Una libertad que, en términos de empoderamiento, supone llegar a la reflexión personal por parte del individuo

13 Young (1988) realiza una distinción entre el concepto "condición sociocultural", correspondiente a la situación material en la que se encuentran las mujeres con respecto a los hombres en relación con determinados indicadores de desarrollo como pueden ser la salud, la educación o la política, y el concepto "posición sociocultural", correspondiente a la situación inmaterial, relacionada con el imaginario colectivo, en la que se encuentran las mujeres con respecto a los hombres en relación con determinados ámbitos como pueden ser, por ejemplo, el estatus familiar o comunitario, la valorización las funciones realizadas, etcétera. 
sobre su propia capacidad para poder deliberar, es decir, tomar conciencia como individuo. El empoderamiento, visto desde la perspectiva de género, es considerado por Schuler (1997) como una evolución en la concienciación de las mujeres sobre sí mismas que tiene como resultado el incremento en la capacidad de configuración de sus propias vidas y que hace alusión a tres tipos de poder: autoempoderamiento (poder interior), empoderamiento colectivo y empoderamiento para la transformación.

Por otro lado, la "estrategia de transversalidad" ("mainstreaming") permite incluir la perspectiva de género en todos los sectores sociales y políticos y se define como el proceso de valoración de las implicaciones que tiene para los hombres y para las mujeres cualquier acción de desarrollo que se planifique (legislación, políticas o programas) en todas las áreas y en todos los niveles. El término "transversalidad de la perspectiva de género" fue acuñado en la "Cuarta Conferencia Mundial sobre la Mujer" (ONU, 1996), celebrada en Pekín en 1995, aunque no se definió sino hasta la celebración, dos años más tarde, de la sesión denominada “Transversalización de la perspectiva de género en todos las políticas y programas del sistema de las Naciones Unidas" (United Nations Economic and Social Council, 1997).

Por su parte, la "estrategia de equidad de género" coloca el concepto "desarrollo de las mujeres" como un derecho al que es necesario hacer justicia, en virtud de la no discriminación por razón de género, en lugar de verlo sólo como un proceso entorpecido por el patriarcado y el capitalismo. Dicha estrategia ha sido promovida por la ONU a partir de la "Declaración de Beijing” (ONU, 1996), donde se puso de manifiesto que los derechos de la mujer también son derechos humanos.

El concepto "equidad” es un principio jurídico fundamental que presenta sus raíces en valores éticos, morales y políticos y que consta de cuatro características, como señalan D'Elia y Maingon (2004): 1) parte de un principio fundamental en el que nadie debe estar en desventaja; 2) en su puesta en práctica como principio ético elemental, tiene carácter social y no solamente individual; 3 ) como regulador político, incide en la distribución de poder, derechos y oportunidades; y 4) como atributo de jurisprudencia, tiene por función cerrar las diferencias injustas.

En este sentido, el término "equidad" cuenta con dos ejes fundamentales: la "justicia" y la "igualdad". Por un lado, la "justicia", en el contexto del desarrollo socioeconómico, ha sido vinculada al concepto "justicia distributiva", que para John Rawls (1993 [1971]) debería ser entendida como la articulación de la equidad para llegar a concebir una ecuanimidad distributiva que tuviera como principios fundamentales el de la libertad y el de la diferencia. Por otro lado, la "igualdad" es entendida por Santa Cruz (1992) a partir de cuatro principios fundamentales (basados en la reciprocidad y el mutuo reconocimiento): autonomía (la posibilidad de elegir y decidir independientemente); autoridad (la capacidad de ejercicio de poder); equifonía (la posibilidad de emitir una opinión que sea escuchada y considerada como portadora de significado y de verdad) y equivalencia (no ser considerado ni por debajo ni por encima de otro/a).

Asimismo, tal y como apunta Rathgeber (1995), el "enfoque de género en el desarrollo" 
ha recibido las siguientes críticas desde el "feminismo postmoderno" y el "feminismo de la interseccionalidad": 1) ha sido asumido por las agencias internacionales unificando las "voces de las mujeres" en "una única voz" y sin dejar espacio para "otras voces" y 2) las relaciones de subordinación pueden ser explicadas, también, por variables distintas al capitalismo - que no actúa uniformemente en todas las partes del mundo- $y$ al "sistema sexo-género" — que no está configurado de la misma manera en todas las regiones del mundo.

El "enfoque de género en el desarrollo" supone el punto de inflexión definitivo para el inicio de la ruptura del pensamiento androcéntrico en algunas agencias internacionales dedicadas al desarrollo, en lo que se refiere, por lo menos, a un ámbito formal.

En este sentido, por un lado, se identifica en el "sistema sexo-género-economía" la base de la opresión de las mujeres para el impedimento de su desarrollo porque en la configuración de dicho sistema radica la principal barrera para el logro de su bienestar (teniendo en cuenta que la felicidad presenta una base material muy importante determinada por el acceso y el control sobre los recursos socioeconómicos). Por otro lado, se establecen estrategias políticas que buscan transformar las relaciones de poder establecidas entre hombres y mujeres a través de tres ingredientes clave: el "empoderamiento de las mujeres" para la redistribución genérica de poder en las sociedades; la "transversalización de la perspectiva de género", porque, como señala Hasse (1992), nada es de género neutro $y$, por lo tanto, ninguna acción de desarrollo puede reclamar neutralidad, y, finalmente, la "equidad de género", por una cuestión de justicia e igualdad, porque el desarrollo es un derecho fundamental y los derechos humanos también son derechos de las mujeres.

Por último, con base en la clasificación realizada por Pérez Orozco (2005), podría decirse que el "enfoque de género en el desarrollo" se fundamenta esencialmente en los principios de la Economía Feminista de la Conciliación (Eisenstein, 1979), que procura generar una teoría económica alternativa a las teorías androcéntricas pero tomando en consideración algunos antiguos paradigmas de utilidad como, por ejemplo, los derivados del socialismo.

- El enfoque de género y desarrollo humano A partir de 1990 se va fraguando el "enfoque de género y desarrollo humano", el cual intenta unificar los fundamentos del "enfoque de las capacidades", también denominado "enfoque de desarrollo humano", y el "enfoque de género en el desarrollo". El "enfoque de género y desarrollo humano" se encarga de analizar las relaciones de género teniendo en cuenta dos aspectos fundamentales: 1) el impacto diferencial de las políticas de desarrollo en hombres y en mujeres, y 2) el efecto perverso, principalmente para las mujeres, del mantenimiento de las desigualdades de género en relación con el desarrollo humano.

Desde la óptica de Nussbaum (2002 [2000]), para lograr un "enfoque de género y desarrollo humano", el "enfoque de desarrollo humano" debería apostar por la transformación de la percepción que se tiene sobre las mujeres en el desarrollo, dejando de considerarlas como un medio para la obtención 
del desarrollo, a fin de que sea su propio desarrollo el que se convierta en objetivo en sí mismo.

De la Cruz (2007) resume una serie de potencialidades que presenta el "enfoque de desarrollo humano" en relación con el "enfoque de género en el desarrollo": 1) localización de una agenda internacional para el desarrollo humano sensible al género basado en el principio de no discriminación entre hombres y mujeres; 2) acuñación del concepto "conflicto cooperativo" 14 para explicar que el conflicto de intereses entre hombres y mujeres es una constante entre todas aquellas otras características sociales que también provocan conflicto, como es, por ejemplo, la clase social; 3) establecimiento de una valoración positiva de la implicación de los trabajos referidos al cuidado, realizados principalmente por las mujeres, en relación con el desarrollo humano en este punto, la autora denuncia la necesidad de una mejor distribución equitativa de dichos trabajos entre hombres y mujeres-; 4) localización del bienestar como una cuestión objetiva de manera que la posición de las mujeres en dicho bienestar puede medirse a través de indicadores; y 5) el empoderamiento de las mujeres pasa a considerarse como un aumento de sus capacidades y su "agencia" (la "agencia de las mujeres"). ${ }^{15}$

14 El concepto "conflicto cooperativo" fue desarrollado por Sen (1990), a partir del enfoque de negociación de los aspectos materiales en la unidad familiar, teniendo en cuenta las situaciones de tensión que puedan darse, entre hombres y mujeres, en el seno de las familias por el uso de determinados recursos imprescindibles para el desenvolvimiento como pueden ser, por ejemplo, el tiempo, la asignación de ingresos, etc.

15 De la Cruz define la "agencia de las mujeres" como "el proceso a través del cual se toman y se ejecutan las decisiones de manera que desafíen las relaciones de poder" (De la Cruz, 2007: 26).
Por otro lado, la autora expone los siguientes desafíos pendientes del "enfoque de desarrollo humano" en relación con el "enfoque de género en el desarrollo": 1) concluir un modelo de justicia social y género; 2) insuficiente alcance para dar respuesta a los retos de la globalización; 3) riesgo de instrumentalización del enfoque; 4) necesidad de incorporar las esferas de producción y reproducción al "enfoque de desarrollo humano"; y 5) necesidad de operacionalizar el concepto de "libertad" teniendo en cuenta valores tales como la justicia y el cuidado, entre otros.

Por último, el "enfoque de género y desarrollo humano" supone la continuación del trabajo realizado por el "enfoque de género en el desarrollo" en relación con el inicio del fin del androcentrismo en el pensamiento socioeconómico. Sin embargo, ese trabajo de continuación quizá presente como desafío la articulación de un paradigma que, teniendo nuevamente en consideración la clasificación realizada por Pérez Orozco (2005), se acerque al terreno de la Economía Feminista de la Ruptura (Carrasco, 2001) y, por lo tanto, que intente construir una nueva teoría económica rompiendo por completo con los paradigmas económicos androcéntricos existentes (centrando el prisma en el análisis de los procesos de sostenibilidad de la vida).

\section{La medición de las desigualdades}

de género en el desarrollo

A partir de 1990 se postula una nueva forma de medir el desarrollo alejándose de la tradicional medición de los índices de pobreza marcados por el BM. De esta manera, el concepto "desarrollo humano" fue sistematizado en el año 1990 por 
el (PNUD 1990) a través del Índice de Desarrollo Humano, que consiste en un indicador estadístico compuesto por tres parámetros: 1) vida larga y saludable - medido a través de la esperanza de vida - ; 2) educación — medido a través del índice de años promedios de escolaridad-, y 3) nivel de vida digno - medido a través del PIB de un determinado país.

Asimismo, a partir de 1995 el concepto “desarrollo humano", visto desde la perspectiva de género, fue sistematizado por el PNUD (1995), a través del Índice de Desigualdad de Género (IDG) e indicadores relacionados (tasa de mortalidad materna, tasa de natalidad entre las adolescentes, escaños en el parlamento, población con al menos un grado de educación secundaria y tasa de participación en la fuerza de trabajo).

A continuación se ilustran los datos ofrecidos por el PNUD (2014) en relación con los indicadores citados (IDG, IDH, tasa de mortalidad materna, tasa de natalidad entre las adolescentes, escaños en el parlamento, población con al menos un grado de educación secundaria y tasa de participación en la fuerza de trabajo), teniendo en cuenta las siguientes áreas geográficas agrupadas para el análisis: Estados Árabes, Asia Oriental/ Pacífico, Europa/Asia Central, América Latina/ Caribe, Asia Meridional y África Subsahariana (véase tabla 1, página siguiente). 
Tabla 1: Datos sobre género y desarrollo agrupados por áreas geográficas

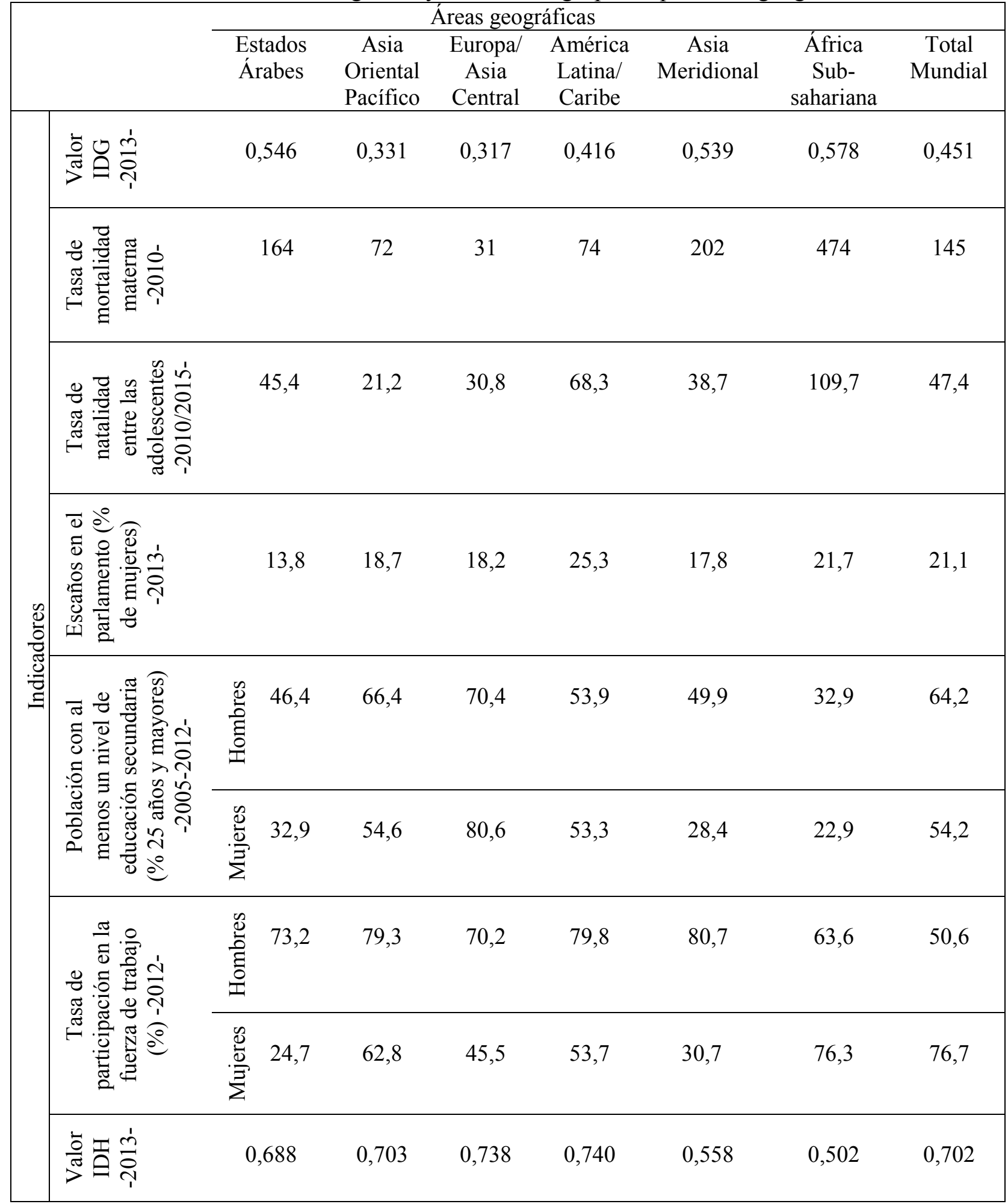

Fuente: PNUD, 2014: 187 - 191 
Tal y como se observa en la tabla anterior, la desigualdad de género, ${ }^{15}$ medida en relación con el desarrollo, presenta multitud de dimensiones relacionadas que se manifiestan de forma distinta según el área geográfica en análisis. Por ejemplo, el porcentaje de mujeres que ocupan escaños en el parlamento en el área geográfica de Europa/ Asia Central es de 16,7\%, mientras que en el área de América Latina/Caribe es de 24,4\%, o en el de África Subsahariana es de 20,9\%. No obstante, puede llegar a considerarse que la medición de "las desigualdades de género en el desarrollo" aún presenta un largo camino empírico, cualitativo y cuantitativo, pendiente de recorrer.

\section{REFLEXIONES FINALES}

Las desigualdades de género son un hecho indiscutible que impide el desarrollo de las mujeres. Sobre dicho hecho se vierten indicadores socioeconómicos que avalan la posición de desventaja sufrida por parte de las mujeres en el camino de su desenvolvimiento. Ahora bien, la perspectiva de género se encuentra lejos de poder ser considerada como una cuestión surgida por "generación espontánea" en el contexto del desarrollo socioeconómico. En esencia, la óptica de género socioeconómica es el resultado de la aplicación de una serie de propuestas feministas (principalmente anteriores al postmodernismo), planteadas a través de movimientos internacionales de mujeres que han luchado, y luchan, por denunciar

15 El concepto "desigualdad de género" es un término maliciosamente unido al concepto "diferencia de género" y constituye esencialmente la minusvaloración psicosociocultural, con implicaciones economicopolíticas y éticas, del grupo socialmente considerado "las mujeres", frente al grupo socialmente considerado "los hombres", tomando como pilar ideológico, de base, el androcentrismo. que las diferencias biológicas entre hombres y mujeres, en cuanto éstas pudieran existir en mayor o menor medida, no son una condición suficiente, y mucho menos una excusa permisible, para la concepción de desiguales derechos, oportunidades y libertades para mujeres y hombres que conviven en una sociedad global monetaria en constante desarrollo. Ha sido, por lo tanto, un logro de las propuestas feministas haber conseguido, al menos a un nivel formal, romper incipientemente con el pensamiento androcéntrico y monopolizador que atesoraron durante décadas las teorías desarrollistas puestas en práctica por la mayoría de las agencias internacionales con peso específico. Sin embargo, dicho logro se encuentra con dificultades para ser tenido en cuenta en la práctica de las políticas gubernamentales fuera del área correspondiente a la retórica.

La agenda internacional de las mujeres en el desarrollo ha venido determinada por una serie de enfoques diferenciados, definidos desde una perspectiva asistencialista y androcéntrica, como es el caso del "enfoque de bienestar"; desde una perspectiva economicista, con una incipiente perspectiva de género, pero con soluciones igualmente androcéntricas, como es el caso del "enfoque de mujeres en el desarrollo"; o desde una perspectiva analítica de ruptura con el androcentrismo con pretensiones transformadoras en torno a las relaciones de poder establecidas en función del género, como es el caso del "enfoque de género en el desarrollo" y el "enfoque de género y desarrollo humano".

Cabe decir, en este sentido, que la diferenciación entre los enfoques descritos 
reside, fundamentalmente, tanto en el tipo de análisis efectuado sobre el "sistema sexo-géneroeconomía" como en las soluciones abordadas para su disfuncionalidad comparativa en relación con los beneficios aportados, respectivamente, para el desarrollo del proyecto vital de hombres y mujeres. Asimismo, es necesario tener en cuenta que la aparición de nuevos enfoques con perspectiva de género convive con la permanencia de los enfoques androcéntricos, porque éstos no se erradican de forma definitiva a pesar de la aparición de enfoques con óptica de género.

Por otro lado, la posibilidad de analizar los fundamentos de las casuísticas que originan las desigualdades de género en el camino del desarrollo, y obrar consecuentemente para la transformación de una situación determinada por la inequidad, supone la posibilidad de comenzar a idear lo que Nussbaum (2002 [2000]) denomina la "agencia personal de las mujeres". Es decir, supone la posibilidad de comenzar a pensar en qué consiste y cómo se puede conseguir la "felicidad de las mujeres" desde un prisma socioeconómico no androcéntrico y, por lo tanto, humano. En este sentido, quizá se haya constatado la necesidad de pasar a tener en cuenta la agenda internacional de las mujeres en el desarrollo en lugar de considerar la parcela que les correspondería a las mujeres en la agenda del desarrollo internacional.

Ahora bien, la importancia de sopesar los enfoques descritos anteriormente en un contexto de incipiente ruptura del pensamiento androcéntrico se fundamenta en la necesidad de reconocer, precisamente, el pasado y el presente androcéntrico de las políticas adoptadas por algunos organismos mundiales. En este sentido, las políticas orientadas para el desarrollo socioeconómico siempre fueron parciales, es decir, o fueron androcéntricas o intentaron adoptar una perspectiva de género. Sin embargo, reconocer la existencia de una ruptura incipiente del pensamiento androcéntrico monopolizador en algunas agencias internacionales equivale únicamente a asegurar la constatación de un rompimiento embrionario del androcentrismo en el pensamiento socioeconómico (incluso con riesgos de retroceso). Las ideologías fluctúan y, por lo tanto, lo que hoy es considerado novedoso y certero, mañana puede ser considerado inapropiado.

Por otro lado, es necesario tener en cuenta que la aplicación de una visión feminista sobre el desarrollo, a través del establecimiento de la perspectiva de género, hace constatar una posición de desventaja de las mujeres con respecto a los hombres en el camino del desarrollo, pero en ningún caso dictamina que el trabajo sobre la transformación de la realidad genérica hacia posiciones de igualdad tenga que ser realizado unilateralmente por parte de las mujeres. En este sentido, la transformación de la realidad genérica reclama una colaboración bilateral entre hombres y mujeres en el camino del desarrollo porque, por un lado, para dar solución a los problemas de las mujeres es necesario tener en cuenta que, como señala Sarah White (1994), los hombres son parte del problema y, por otro lado, la exclusión de los hombres de las acciones de desarrollo puede crear un clima de hostilidad y, como señalan Chant y Gutmann (2000), una sobrecarga de trabajo añadido para las mujeres.

Por último, quizá sea pertinente traer a colación, en este punto, el argumento de Gilman 
(2008 [1898]) sobre la determinante involución humana de un mundo androcéntrico porque, en este sentido, cómo puede llegar a esperarse de la condición humana su superlativo si el camino histórico escogido para su "progreso" parte del principio de discriminación (de género, de clases sociales, de culturas, etcétera), entre las potenciales partes involucradas para su consecución. ¿ 


\section{BIBLIOGRAFÍA}

Amorós, Ana (2007), “La división sexual del trabajo", en Celia Amorós (coord.), 10 palabras claves sobre mujer ( $4^{\mathrm{a}}$ edición, $3^{\mathrm{a}}$ reimpresión). Navarra, Verbo Divino, pp. 257-296.

Appleby, Joyce (1984), Capitalism and a New Social Order. The Republican Vision of the 1970s. New York, New York University Press.

Benería, Lourdes y Gita Sen (1983), “Desigualdades de clases y de género y el rol de la mujer en el desarrollo económico: implicaciones teóricas y prácticas”, en Mientras Tanto, núm. 15, pp. 91-113.

Boserup, Ester (1993 [1970]), La mujer y el desarrollo económico (trad. María Luisa Serrano). Madrid, Minerva.

Brown Blackwell, Antoinette (1875), The Sexes Throughout Nature. New York, Putnam's Sons.

Carrasco, Cristina (2001), “La sostenibilidad de la vida humana: ¿un asunto de mujeres?”, en Mientras Tanto, núm. 82, pp. 43-70.

Chant, Sylvia (2004), "Dangerous Equations? How Female-headed Households Became the Poorest of the Poor: Causes, Consequences and Cautions", en IDS Bulletin, vol. 35, núm. 4, pp. 19-26. DOI: 10.1111/j.1759-5436.2004.tb00151.x

Chant, Sylvia y Matthew Gutmann (2000), Mainstreaming men into Gender and Development. Oxford, Oxfam GB.

Cobo, Rosa (2007), “Globalización y nuevas servidumbres de las mujeres”, en Celia Amorós y Ana de Miguel (eds.), Teoría feminista: de la Ilustración a la globalización. De los debates sobre el género al multiculturalismo (vol. 3, 2a edición). Madrid, Minerva Ediciones, pp. 265-300.

D’Elia, Yolanda y Thais Maingon (2004), La equidad en el Desarrollo Humano: estudio conceptual desde el enfoque de igualdad y diversidad. Caracas, PNUD. 
Davis, Angela (2005 [1981]), Mujeres, raza y clase (trad. Ana Varela). Madrid, Ediciones Akal.

De la Cruz, Carmen (2007), Género, Derechos y Desarrollo Humano. San Salvador, PNUD, consultado el 6 de diciembre de 2014, URL: http:/www.otrodesarrollo.com/desarrollohumano/ delaCruzGeneroDesarrolloHumano.pdf.

Durán, María Ángeles (2012), El trabajo no remunerado en la economía global. Bilbao, Fundación BBVA.

Eisenstein, Zillah (1979), Capitalist Patriarchy and the Case For Socialist Feminism. New York, Monthly Review Press.

Engels, Friedrich (2001 [1884]), El origen de la familia, la propiedad privada y el estado. Del socialismo utópico al socialismo cientifico (trad. P. J. Domínguez). Madrid, Mestas.

Food and Agriculture Organization of the United Nations (2011), The state of food and agriculture 20102011. Women in Agriculture. Closing the gender gap for development. Roma, FAO, consultado el 21 de junio de 2015, URL: http://www.fao.org/docrep/013/i2050e/i2050e.pdf.

Freire, Paulo (2009 [1965]), La educación como práctica de la libertad (trad. Lilian Ronzoni). Madrid, Siglo XXI.

García-Mina, Ana, y María José Carrasco (eds.) (2004), Género y desigualdad: la feminización de la pobreza. Madrid, Universidad Pontificia de Comillas.

Giles-Vernick, Tamara, y James L. A. Webb (2013), Global Health in Africa: Historical Perspectives on Disease Control. Ohio, Ohio University Press.

Gilman, Charlotte Perkins (2008 [1898]), Mujeres y Economía: Un estudio sobre la relación económica entre hombres y mujeres como factor de la evolución social (Trad. Empar Barranco). Valencia, Publicaciones de la Universidad de Valencia.

Gilman, Charlotte Perkins (2011 [1911]), The Man-Made World: or Our Androcentric Culture (Reimpreso). Auckland, The Floating Press. 
Hartman, Heidi (1994), “Capitalismo, patriarcado y segregación de los empleos por sexo”, en Cristina Borderías, Cristina Carrasco y Carme Alemany (comps.), Las mujeres y el trabajo: rupturas conceptuales. Barcelona, Icaria, pp. 253-294.

Hasse, Cathrine (1992), "Target Group, Gender and Visibility", en Ibis Projects, Report for Ibis. Copenhagen, IBIS.

Hernández, Itziar (1999), “Desigualdad de género en desarrollo”, en Paloma de Villota (ed.), Globalización y género. Madrid, Síntesis, pp. 67-80.

Humphries, Jane (ed.) (1995), Gender and Economics. Aldershot, Edward Elgar.

International Labour Office (1977), Employment, growth, and basic needs: A one-world problem: the international "basic-needs strategy" against chronic poverty. London, Praeger Publishers, consultado el 10 septiembre 2014 URL: http://www.ilo.org/public/libdoc/ilo/1977/77B09_355_engl.pdf.

Kawachi, Ichiro y Sarah Wamala (2007), Globalization and Health. Oxford, Oxford University Press.

Lewis, William Arthur (1969), Some aspects of economic development. Accra, Ghana Publishing Co.

Maguire, Patricia (1984), Women in Development: An Alternative Analysis. Amherst, M.A., Center for international Education.

Medeiros, Marcelo y Joana Costa (2008), “Is There a Feminization of Poverty in Latin America?”, en World Development, vol. 36, núm. 1, pp. 115-127.

Mies, Miria (1998), Patriarchy and Accumulation. On A World Scale: Women in the International Division of Labour. London, Zed Books.

Mohanty, Chandra Talpade (1991), "Under Western Eyes: Feminist Scholarship and Colonial Discourses", en Chandra Talpade Mohanty, Ann Russo y Lourdes M. Torres (eds.), Third World Women and the Politics of Feminism. Bloomington, Indiana University Press, pp. 333-358.

Moser, Caroline (1993), Gender Planning and Development: Theory, Practice and Training. London, Routledge. 
Nussbaum, Martha Craven (2002 [2000]), Las mujeres y el desarrollo humano. El enfoque de las capacidades (Trad. Roberto Bernet). Barcelona, Herder.

Organización de Estados Americanos (2007), Principios de Yogyakarta. Principios sobre la aplicación de la legislación internacional de derechos humanos en relación con la orientación sexual y la identidad de género. Columbia, OEA, consultado el 11 de julio de 2014 URL: http://www.oas.org/dil/esp/orientacion_sexual_Principios_de_Yogyakarta_2006.pdf.

Organización de las Naciones Unidas (1995), Informe de la Conferencia Internacional sobre la Población y el Desarrollo, El Cairo, 5-13 de septiembre de 1994, A/CONF.171/13/Rev.1. Nueva York, ONU, consultado el 9 de septiembre de 2014, URL:

https://www.unfpa.org/webdav/site/global/shared/documents/publications/2004/icpd_spa.pdf.

Organización de las Naciones Unidas (1996), Informe de la Cuarta Conferencia Mundial sobre la Mujer, Pekín, 4-15 de septiembre de 1995, A/CONF.177/20/Rev.1. Nueva York, ONU, consultado el 22 de diciembre de 2010, URL:

http://www.un.org/womenwatch/daw/beijing/pdf/Beijing\%20full\%20report\%20S.pdf.

Organization for Economic Co-operation and Development (1984), Economic outlooks. OECD, Paris.

Pérez Orozco, Amaia (2005), “Economía del género y economía feminista, ¿conciliación o ruptura?”, en Revista Venezolana de Estudios de la Mujer, vol. 10, núm. 24, pp. 43-64.

Programa de Naciones Unidas para el Desarrollo (1990), Informe sobre Desarrollo Humano 1990. Definición y medición del desarrollo humano. Nueva York, PNUD, consultado el 9 de septiembre de 2014, URL: http://hdr.undp.org/sites/default/files/hdr_1990_es_completo_nostats.pdf.

Programa de Naciones Unidas para el Desarrollo (1995), Informe sobre desarrollo humano: La revolución hacia la igualdad en la condición de los sexos. Nueva York, PNUD, consultado el 10 de noviembre de 2014, URL: http://hdr.undp.org/sites/default/files/hdr_1995_es_completo_nostats.pdf.

Programa de Naciones Unidas para el Desarrollo (2014), Informe sobre desarrollo humano 2014. Sostener el Progreso Humano: Reducir vulnerabilidades y construir resiliencia. Nueva York, PNUD, consultado el 1 de noviembre de 2014, URL:

http://www.undp.org/content/dam/undp/library/corporate/HDR/2014HDR/HDR-2014-Spanish.pdf. 
Rathgeber, Eva M. (1989), WID, WAD, GAD: Trends in research and practice. Ottawa, IDRC.

Rathgeber, Eva. M. (1995), "Gender and Development in Action”, en Marianne H. Marchand y Jane L. Parpat (eds.), Feminism, Postmodernism, Development. London, Routledge, pp. 204-220.

Rawls, John (1993 [1971]), Teoría de la Justicia (Trad. María Dolores González). Buenos Aires, Fondo de Cultura Económica.

Rubin, Gayle (1975), “The Traffic in Women: Notes on the 'Political Economy' of Sex”, en Rayna R. Reiter (ed.), Toward an anthropology of women. New York, Monthly Review Press, pp. 157-210.

Santa Cruz, Isabel (1992), "Sobre el concepto de igualdad: algunas observaciones", en ISEGORIA, vol. 6, pp. $145-152$.

Schuler, Margaret (1997), "Los derechos de las mujeres son derechos humanos: la agenda internacional del empoderamiento", en Magdalena León (comp.), Poder y empoderamiento de las mujeres. Bogotá, Tercer Mundo, pp. 29-54.

Sen, Amartya (1985), Commodities and Capabilities. Oxford, North-Blackwell.

Sen, Amartya (1990), “Gender and Cooperative Conflicts", en Irene Tinker (ed.), Persistent Inequalities: Women and World Development. New York, Oxford University Pres, pp. 123-149.

Sen, Amartya (1991), "Faltan más de 100 millones de mujeres", en Ximena Bunster, Cynthia Enloe y Regina Rodríguez (eds.), La mujer ausente: Derechos Humanos en el mundo (Trad. Grecia Pérez de Arce). Santiago de Chile, ISIS Internacional, pp. 27-40.

Sen, Gita y Caren Grow (1987), Development, Crises, and Alternative Visions: Third Word Women's Perspectives. New York, Monthly Review Press.

Staudt, Kathleen (1986), "Women, Development and the State: On the Theoretical Impasse", en Development and Change, vol. 17, pp. 325-333. DOI: 10.1111/j.1467-7660.1986.tb00243.x. 
United Nations (1976), Report of the Word Conference of the International Women's Year, Mexico City, 19 June-2 July 1975, E/CONF. 66/34. New York, UN, consultado el 11 de septiembre de 2013, URL: http:/www.un.org/womenwatch/daw/beijing/otherconferences/Mexico/Mexico\%20conference\%20 report\%20optimized.pdf.

United Nations (1980), Report of the Word Conference of the United Nations Decade for Women: Equality, Development and peace. Copenhagen, 14 to 30 July 1980, A/CONF. 94/35. New York, UN, consultado el 11 de septiembre de 2013, URL:

http://www.un.org/womenwatch/daw/beijing/otherconferences/Copenhagen/Copenhagen\%20Full\%20 Optimized.pdf.

United Nations (1986), Report of the Word Conference to review and appraise the achievements of the United Nations Decade for Women: Equality, Development and Peace, Nairobi, 15-26 July 1985, A/CONF. 116/28/Rv.1. New York, UN, consultado el 11 de septiembre de 2013, URL:

http://www.un.org/womenwatch/daw/beijing/otherconferences/Nairobi/Nairobi\%20Full\%20Optimized.pdf.

United Nations Economic and Social Council (1997), UN Economic and Social Council Resolution 1997/2: Agreed Conclusions, 18 July 1997. Mainstreaming the gender perspective into all policies and programmes in the United Nations System. Geneva, ECOSOC, consultado el 10 de septiembre de 2013, URL: http://www.un.org/womenwatch/osagi/pdf/ECOSOCAC1997.2.PDF.

Ward, Kathryn B. y Jean Larson Pyle (1995), “Gender, Industrialization, and Development", en Development, vol. 1, pp. 67-71.

White, Sarah (1994), "Making men an issue: gender planning for 'the other half"”, en Mandy Macdonald (ed.), Gender Planning in Development Agencies. Meeting the Challenge. Oxford, Oxfam, pp. 98110.

Whitehead, Ann (2006 [1979]), "Some Preliminary Notes on the Subordination of Women", en IDS Bulletin, vol. 37, núm. 4, pp. 24-27.

World Bank (1979a), Recognizing the “Invisible” Women in Development: The World Bank's Experience. Washington, D.C., WB, consultado el 9 de septiembre de 2014, URL:

http://www-wds.worldbank.org/external/default/WDSContentServer/WDSP/IB/1999/11/18/000178830_9 8101901520536/Rendered/PDF/multi_page.pdf. 
World Bank (1979b), Work Development Report. Washington, D.C.: WB, consultado el 13 de abril de 2014, URL: https://openknowledge.worldbank.org/bitstream/handle/10986/5962/WDR\%201979\%20\%20 English.pdf?sequence=1.

World Bank (1989), Sub-Saharan Africa: From Crisis to Sustainable Growth. A long-term Perspective Study. Washington, D.C. WB, consultado el 13 de abril de 2014, URL:

http://www-wds.worldbank.org/external/default/WDSContentServer/WDSP/IB/1999/12/02/0001 78830_98101901364149/Rendered/PDF/multi0page.pdf.

World Bank (1990), World Development Report 1990. World Development Indicators. Oxford, Oxford University Press.

Young, Kate (1988), “Introduction: reflections on meeting women's needs”, en Kate Young (ed.), Women and Economic Development: Local, Regional and National Planning Strategies. Oxford, Berg Publishers, pp. 1-30.

Fecha de recepción: 24 de febrero de 2015

Fecha de aceptación: 28 de octubre de 2015 